\title{
ELECCIONES EN ESTADOS UNIDOS: REPRESENTACIONES SOCIALES DEL VOTO LATINO EN FAVOR DE TRUMP A TRAVÉS DEL ANÁlisis leXicométrico de la PRENSA digital EN FACEBOOK
}

\author{
Elections in the United States: Social \\ Representations of the Latino Vote in Favor of Trump \\ through the Lexicometric Analysis of the Digital Press \\ ON FACEBOOK
}

\author{
Gustavo Adolfo Liloff* \\ María Estela Ortega Rubi*** \\ doi: https://doi.org/10.31644/ED.V8.N2.2021.A05
}

\begin{abstract}
Resumen: La presente investigación tuvo como objetivo identificar las representaciones sociales del voto latino en favor de Trump a partir del análisis del post publicado luego de las elecciones por el medio digital PlayGround, como así también revelar las explicaciones que se les atribuyen. Se plantea una metodología exploratoria con un diseño explicativo secuencial cuantitativocualitativo. La muestra estuvo compuesta por 1396 comentarios directos — 419 mujeres, 890 varones y 87 indeterminados_-, tomados desde la página de Facebook del medio digital en cuestión, bajo el posteo "Pregunta para latinoamericanos". Se evidencian organizaciones representacionales diferentes según el género de los participantes. Para los varones el voto latino hacia Trump surge como respuesta a la percepción de un otro latino, indocumentado o ilegal, como un extranjero enemigo, aquella competencia que hay que eliminar, mientras que para las mujeres surge a partir de la figura latina que se ve como superior por haber resuelto su estatus legal, a la vez que se expone con una visión clasista xenófoba de un nacionalismo exacerbado. En ambos casos, el miedo a repetir historias del comunismo o socialismo de sus países de origen se transforma en un fuerte proveedor de identidad del votante latino de Trump.
\end{abstract}

Palabras clave: representaciones sociales, voto latino, redes sociales, Trump, Iramuteq.

\footnotetext{
* Dr. en Ciencias de la Educación, profesor e investigador independiente en la Dirección General de Cultura y Educación, Buenos Aires, Argentina. ORCiD: https://orcid.org/0000-0003-4419-6925 Correo-e: gustavoliloff@ yahoo.com.ar.

** Dra. en Psicología Social, profesora investigadora del Instituto de Investigaciones Sociales, Universidad Autónoma de Nuevo León, Monterrey, México. ORCiD: https://orcid.org/0000-0001-5913-7683 Correo-e: estela_ort_rubi@ hotmail.com.
}

Fecha de recepción: 27/01/2021. Fecha de aceptación: 24/06/2021. Fecha de publicación: 30/07/2021.

(cc) BY-NC-ND

EntreDiversidades. Revista de Ciencias Sociales y Humanidades, Vol. 8, Núm. 2 (17), julio-diciembre 2021. Páginas: 99-118 ISSN-e: 2007-7610. https://doi.org/10.31644/ED.V8.N2.2021.A05 
Abstract: The goal of this research was to identify the social representations of the Latino vote in favor of Trump from the analysis of the post published after the elections by the digital medium PlayGround, as well as to make explicit the explanations attributed to them. An exploratory methodology is proposed with a quantitative - qualitative sequential explanatory design. The sample consisted of 1396 direct comments - 419 women, 890 men and 87 indeterminate -, taken from the Facebook page of the digital medium in question, under the post "Question for Latin Americans". Different representational organizations are specified according to the gender of the participants. For men, the Latino vote towards Trump arises as a response to the perception of another Latino, undocumented or illegal, as a foreigner as an enemy, that competition that must be eliminated. While for women it arises from the Latin figure who is seen as superior for having resolved his legal status, at the same time that he is exposed with a xenophobic class vision of an exacerbated nationalism. In both cases, the fear of repeating stories of communism or socialism in their home countries becomes a strong provider of identity for the Latino voter for Trump.

Keywords: social representations, latin vote, social media, Trump, Iramuteq.

\section{Introducción}

Vivimos un presente donde los procesos electivos democráticos se ven marcados por verdaderas contiendas que apelan a las más variadas estrategias para volcar la balanza a favor de uno de los contrincantes, en los que cada uno de los equipos de campaña se focaliza en los sentimientos, necesidades y valores de los diferentes grupos de votantes, de tal manera que no solo se construye una determinada figura de los propios candidatos, sino también de su opositor.

En este sentido, pudimos observar los comicios quizás más trascendentes en la historia contemporánea de Estados Unidos. Por primera vez 32 millones de votantes latinos se encontraron en condiciones de sufragar, lo que representó un $15 \%$ más que en las últimas elecciones presidenciales del 2016, convirtiéndose en la primera minoría étnica con peso electoral superando a los afroestadounidenses (Cilluffo y Fry, 2019).

Por un lado, se presentaba el candidato del partido demócrata Joe Biden, y por el otro, el del partido republicano, y entonces presidente, Donald Trump, quienes no ajenos a la magnitud de votantes de origen latino trataron por diversos medios y estrategias captarlos, ya sea a través de diferentes meetings de propuestas e intercambio con los mismos, o mediante anuncios con acento cubano, puertorriqueño y mexicano, entre otros (Medina, 2020).

Es importante observar que en estas elecciones dos de cada tres latinos elegibles para votar viven en solo cinco estados: 7,9 millones en California, 5,6 millones en Texas, 3,1 millones en Florida, 2,0 millones en New York y 1,2 millones en Arizona. Además, los latinos conforman la mayor proporción de votantes en Nuevo México, 43\%, California, 30\%, Texas, 30\%, Arizona, 24\% y Florida, 20\% (Noe-Bustamante, Budiman, y López, 2020).

EntreDiversidades. Revista de Ciencias Sociales y Humanidades, Vol. 8, Núm. 2 (17), julio-diciembre 2021. Páginas: 99-118 ISSN-e: 2007-7610. https://doi.org/10.31644/ED.V8.N2.2021.A05 
En este contexto, si bien el entonces presidente Donald Trump no logró ser reelecto, hubo quienes se sorprendieron ante el aumento en el apoyo del voto latino, en comparación con el 2016, lo que le permitió llevarse dos estados claves: Texas y Florida.

Así, según lo manifiesta Castro (2020), la sorpresa radicaba fundamentalmente en las políticas antiinmigratorias basadas en una retórica de corte racista y la exacerbación del nacionalismo que se ponían de manifiesto en los discursos de Trump, lo que podría hacer presuponer que la comunidad latina se sintiera disconforme y volcara su voto hacia el partido demócrata, pero ello no fue de esta manera.

Planteados los antecedentes, el propósito de nuestro trabajo es identificar las representaciones sociales del voto latino hacia Trump; es decir, las explicaciones y significados que el sentido común de los propios latinoamericanos le atribuyen, analizando a su vez las posibles similitudes o diferencias desde una perspectiva de género, como así también el posible origen en que se sustenta este tipo de sufragio, para que de cierta manera se puedan explicar y comprender los factores que intervienen en su construcción. Para ello, tomamos las interacciones directas — comentariosque se expresan al pie del post publicado el 6 de noviembre del 2020 en la plataforma de Facebook del medio digital de habla hispana PlayGround, en referencia al apoyo latino al actual presidente Donald Trump en las elecciones realizadas recientemente en Estados Unidos.

\section{El contexto electoral}

Hablar del contexto electoral, y en particular del voto latino, nos vuelve la mirada sobre un grupo de alta complejidad en cuanto a que no pueden ser tomados como una comunidad homogénea ni con las mismas necesidades ni expectativas, por lo que no se puede esperar que el voto latino sea un voto en bloque.

Remitirnos al grupo de latinos es hacerlo a un mosaico de identidades en torno a esta etiqueta donde se consideran a una de cada cinco personas que hoy reside en Estados Unidos. Asimismo, es un grupo de amplia variabilidad con respecto a su lugar de residencia, su país de origen y su situación familiar. De los 32 millones de latinos que hemos mencionado que se encuentran en condiciones de sufragar, aproximadamente el $59 \%$ son de origen mexicano o mexicano-estadounidense, $14 \%$ puertorriqueños, $5 \%$ de procedencia cubana y $22 \%$ de otros orígenes (Sulbarán, 2020).

Son, entre otras, las características de la nacionalidad las que utilizaron cada uno de los candidatos para construir una determinada figura retórica que apelara a las diferencias que se expresan en cada grupo, en donde a modo de ejemplo exponemos el discurso de Trump que distinguía entre los buenos y malos latinos y se dirigía preferencialmente a los votantes de origen cubano y venezolanos predominantes en el estado de Florida. O, por otra parte, el discurso de Biden centrado en los hijos de la primera o segunda generación de inmigrantes, muchos de ellos nacidos en territorio estadounidense, a punto tal de destacar que el exitoso futuro de los Estados Unidos dependería de que la comunidad latina pueda acceder a las oportunidades con las herramientas que necesitan para lograr sus metas (Corona, 2020).

EntreDiversidades. Revista de Ciencias Sociales y Humanidades, Vol. 8, Núm. 2 (17), julio-diciembre 2021. Páginas: 99-118 ISSN-e: 2007-7610. https://doi.org/10.31644/ED.V8.N2.2021.A05 
Asimismo, ciertas estrategias se focalizaron en remarcar aspectos de las crisis políticas latinoamericanas, tales como los regímenes castristas o chavistas, apelando al miedo de los inmigrantes a vivir nuevamente esas experiencias de las cuales huyeron. En ese caso, el discurso de Trump se centró en este tipo de retórica, procurando construir una figura de Biden como simpatizante de los gobiernos autoritarios de Latinoamérica y con la posibilidad de que bajo su mandato los Estados Unidos adoptarían un tipo de gobierno socialista.

Por su parte, Biden rebatía los argumentos de Trump recurriendo a los valores y sentido de pertenencia, configurando su discurso en torno a la figura del ciudadano estadounidense, postulando que por el hecho de pertenecer debemos ser respetados, y, en este sentido, ubicando el gobierno del presidente Trump como una dictadura (Castro, 2020). De cierta manera, los temas como salud, empleo, educación, política migratoria, etc., son asuntos que en varias ocasiones quedaban relegados o abordados desde una perspectiva parcializada y que pudiéramos decir que apenas se tomaron de manera firme en el último trayecto de la campaña electoral.

En suma, y dadas las características del sistema de elección indirecto de Estados Unidos a través de un Colegio Electoral, cada estado obtiene una cantidad de miembros proporcional a la representación que tiene en el Congreso, donde luego esos electores elegirán al presidente, y el candidato que logre más de la mitad - 270 — de los votos se convierte en ganador de la contienda. En números concretos, Joe Biden obtuvo 306 electores, transformándose en el nuevo presidente de los Estados Unidos, contra 232 electores de Donald Trump.

Pero en este contexto debemos destacar la polémica que ha desatado en la propia comunidad latina, en cuanto al aumento de votantes latinos que se expresaron a favor de Trump, pasando del 28\% en las elecciones del 2016 al 32\% en las del 2020 (Padden y Balderas, 2020). Esto ocasionó un arduo debate en las redes sociales.

Consecuentemente, el 6 de noviembre del 2020 el medio digital en español PlayGround, a través de su página de Facebook, planteaba la siguiente inquietud: "Pregunta para latinoamericanos: ¿Por qué Trump batió su récord de votos latinos, aun con políticas antimigrantes y racistas?” Cuestión que en menos de cinco horas desataba más de 5300 comentarios, 6600 reacciones emocionales —emoticones_, y llevaba a compartir dicho post por más 918 usuarios de la red social. Claramente se puso de manifiesto el fuerte interés social que despierta la pregunta en cuestión, en la que un gran número de lectores sintió la necesidad de expresar su pensamiento al respecto.

\section{Representaciones sociales y las plataformas digitales}

Detenernos en analizar cómo las personas construyen su pensamiento y qué hay detrás de este, en cuanto al voto latino hacia Trump, es poner de manifiesto el propio pensamiento social. En otras palabras, supone evidenciar las representaciones sociales que se encuentran en tensión entre los diferentes grupos.

Ortega (2015 [2011]: 227) expone que las representaciones sociales dan lugar a "una visión de la realidad común a un grupo social o un grupo culturalmente dado". En este mismo sentido, la realidad asume características de aquellos ojos que la perciben. Por su parte, Moscovici (1981)

EntreDiversidades. Revista de Ciencias Sociales y Humanidades, Vol. 8, Núm. 2 (17), julio-diciembre 2021. Páginas: 99-118 ISSN-e: 2007-7610. https://doi.org/10.31644/ED.V8.N2.2021.A05 
establece que las mismas son un conjunto de explicaciones que se generan en la vida cotidiana a través de las comunicaciones interpersonales, o lo que también podría comprenderse como el saber del sentido común. En forma concisa, Jodelet (2017 [1989]: 53) las define como "una forma de conocimiento, socialmente elaborado y compartido, que tiene un objeto práctico y contribuye a la construcción de una realidad común a un grupo social”.

Por tanto, las representaciones sociales van a permitir organizar la realidad y a la vez codificarla de manera similar entre los diferentes miembros del grupo, de modo que aquello que resulta extrańo se convierta en familiar, al igual que lo invisible en perceptible (Farr, 1986). En otras palabras, aquellos objetos (materiales, simbólicos o imaginarios) significativos o situaciones que se experimenten por el grupo como amenazantes, que despierten conflictos o generen escenarios de experiencias dolorosas, propiciarán el proceso de constitución de la representación social. Asimismo, este nuevo objeto se constituirá como objeto representacional anclándolo en el universo de conocimiento colectivo, actuando a la vez como refuerzo y legitimación de sus posiciones (Ortega y Liloff, 2020).

En este sentido, podemos observar que, en un contexto determinado, las maneras en que las personas se comporten no estarán en relación con las características objetivas de la situación, sino por el contrario, se producirán en relación directa con las formas de representarse esa situación (Abric, 2017 [1989]). Así, cada grupo social se conformará en base a la unificación de objetos y acontecimientos a través de los procesos de categorización social, agrupando a aquellas personas con las mismas creencias, valores e intenciones.

En consecuencia, las formas en que cada persona representa aquello que asume como realidad quedarán ceñidas, en parte, a la identidad social de su grupo — o grupos— de pertenencia, es decir, al significado valorativo y emocional asociado a dicha pertenencia (Tajfel, 1984). De esta manera, las divisiones sociales entre "un nosotros" y "un ellos" dependerán de las categorizaciones sociales ancladas en las distinciones entre los diferentes grupos. En otras palabras, en aquellas cogniciones que compongan las representaciones sociales de los grupos.

Por otra parte, una cuestión no menor que debemos considerar a la hora de pensar este tipo de objetos representacionales es la incidencia en la conformación de la representación social que tendrán los medios de comunicación masiva, en cuanto a establecer los criterios, ámbitos y preeminencia en el debate social y, en nuestro caso en particular, en la agenda del debate electoral, a punto tal de poner en tensión aquellas figuras o posiciones retóricas que cada uno de los candidatos va formando a lo largo de la contienda electoral.

Esta influencia se ha visto ampliamente modificada en los últimos años, en la que la relación productores y consumidores de noticias ha asumido profundos cambios como consecuencia del uso de internet y de las redes sociales masivas, tales como Facebook, Instagram, Twitter, etc., pasando de una relación eminentemente vertical a otra masiva, instantánea y de interacción (Etura, Gutiérrez y Martín, 2017).

De esta manera, las representaciones sociales se modelan en las interacciones de los diferentes discursos que cobran voz en el debate público, pero obviamente a través de los distintos soportes y plataformas mediáticas que les permiten una amplia difusión. Así, las redes sociales se convierten en verdaderos amplificadores de voces de los diferentes grupos de personas que integran la

EntreDiversidades. Revista de Ciencias Sociales y Humanidades, Vol. 8, Núm. 2 (17), julio-diciembre 2021. Páginas: 99-118 ISSN-e: 2007-7610. https://doi.org/10.31644/ED.V8.N2.2021.A05 
sociedad, es decir, en verdaderas arenas donde se ponen de manifiesto el sentido común de estos grupos, y, por tanto, en un terreno fértil a la hora de procurar su investigación.

Moscovici (1979) puso de manifiesto la importancia de los medios de comunicación masiva tales como la prensa escrita, y en la actualidad encontramos en los post de las redes sociales como Facebook un amplio espectro de discursos que conforman representaciones sociales de diferentes grupos. Pero también debemos observar que todo medio digital de noticias, en concordancia con su línea editorial, expone una manera particular de interactuar con sus lectores, ya sea en modos de presentar las noticias o, como en el caso de estudio, en formas de preguntar a sus lectores destacando ciertos atributos del objeto de referencia en esa pregunta; esto, de hecho, puede conducir a una determinada representación del objeto (Rouquette, 1986).

Observamos que PlayGround plantea a través del post en cuestión una intencionalidad de abrir el debate y posicionarse dentro del mundo hispano hablante — público objetivo de su editorial — presentando una pregunta que, desde su propia formulación, asume una posición determinada: considerar la gestión del Trump como ultraconservadora, independientemente de otros tipos de análisis, dejando ver en la propia pregunta una tendencia ideológica del medio en cuestión. En otras palabras, cada persona que interactúa desde la lectura de un determinado medio digital queda expuesta no solo a las opiniones de este medio, sino también a una determinada manera de ver e interrelacionarse con la realidad (Gutiérrez y Cuevas, 2012).

Desde esta perspectiva podemos visualizar a Facebook como una red social masiva que, a su vez, es utilizada como plataforma de difusión por varios medios digitales, convirtiéndose en una enorme caja de amplificación y resonancia de ciertos aspectos que cobran interés para un determinado grupo editorial, entre ellos PlayGround, referente de nuestro objeto de investigación.

Esta situación configura una manera de interacción directa de las personas con las noticias digitales, permitiéndoles manifestar comentarios, creencias, opiniones, valores y actitudes, es decir, pone al descubierto las representaciones sociales que se encuentran en juego. Así, cuando las características de la realidad se tornan relevantes, ya sea por el dolor social que causa, porque apelan a los miedos sociales o porque trasgrede las normas, estas se visibilizarán de manera permanente a través de los medios de comunicación masiva mediante el uso de diversas plataformas que operan en su difusión, a punto tal que movilizará a los sujetos y, con ello, a los grupos que estos integren (Moscovici, 2005 [1985]).

\section{Entre el nacionalismo y el miedo al inmigrante: la apelación populista de Trump}

Apelar al nacionalismo como construcción retórica significa tomar el complejo entramado de raíces simbólicas, prácticas sociales, ritos y representaciones ancladas a un devenir histórico que a manera de capas unas tras otras constituyen lo que caracteriza a un macrogrupo social que conforma una nación.

Este llamamiento al nacionalismo se evidenció desde el principio en las construcciones discursivas de Trump, basta con recordar un fragmento de su disertación en la aceptación de la nominación por parte del Partido Republicano en el 2016: "La diferencia más importante

EntreDiversidades. Revista de Ciencias Sociales y Humanidades, Vol. 8, Núm. 2 (17), julio-diciembre 2021. Páginas: 99-118 ISSN-e: 2007-7610. https://doi.org/10.31644/ED.V8.N2.2021.A05 
entre nuestro plan y el de nuestros oponentes es que nuestro plan pondrá America First. El americanismo, no el globalismo, será nuestro credo" (Politico, 2016).

Pero este nacionalismo en la retórica de Donald Trump se expresaba, en más de una oportunidad, en términos extremos exponiendo actitudes xenófobas y etnocentristas, construyendo fuertes fronteras simbólicas entre un ellos, los extranjeros —inmigrantes generalmente latinos-, y un nosotros —el verdadero estadounidense-.

En cierto sentido, el nosotros se construye sobre la base de una clara diferenciación anclada a un sentimiento de superioridad en contraposición a un otro, que por su sola condición de inmigrante se objetiva como una persona de estatus inferior. Así, el otro se transforma en alguien extraño y temido, hasta el extremo de ser objeto de actos violentos, despojándolos de toda subjetividad, transformándolo en una especie distinta a ese "nosotros nacionalista".

Yakushko (2009: 37) expone esta idea con toda claridad: "los inmigrantes se asocian repetidamente con la economía en declive, superpoblación, contaminación, aumento de la violencia, [...] erosión de los valores culturales y terrorismo. Los individuos a menudo son retratados como criminales, pobres, violentos y sin educación”. Sin embargo, es importante tener en cuenta que ese sentimiento nacionalista extremo también se encuentra en aquellos que de alguna manera se sienten desplazados, tolerando ciertas desventajas sociales, conformando grupos homogéneos, en relación con su constitución racial, en pequeños poblados, de escasa movilidad social, y generalmente exhiben menores niveles educativos, a los que podríamos denominar como sectores o clases populares (Rothwell y Diego-Rosell, 2016; Ariza y Gutiérrez, 2020). Así, estos grupos se perciben como afectados por aquel otro extrańo y ajeno a su nación, ya sea en lo inmediato o en sus perspectivas de futuro, y justamente este extrańo logra objetivarse en la retórica discursiva de Trump a través de un objeto concreto, "la figura del inmigrante".

En suma, la retórica nacionalista exacerbada se constituye mediante un discurso antiinmigrante que, con frecuencia, se centra en justificar la legitimidad de las reacciones prejuiciosas que se activan cuando la ideología, como el etnocentrismo, se relaciona directamente con una amenaza a nivel personal o grupal que, como expusimos, cala profundo en aquellos sectores que hemos denominado populares.

\section{Metodología}

Considerar el fenómeno que abordamos presente en diferentes grupos bajo una misma etiqueta determinada por la palabra "latinos", significa poder llegar a dar cuenta de cómo estos grupos llevan adelante la construcción de sentidos en referencia a nuestro objeto de investigación. De cierta manera, podemos observar que este mosaico de identidades, que hoy representa la primera minoría étnica de peso electoral en Estados Unidos, hizo que las últimas elecciones asumieran características inéditas.

Así, nuestra investigación se centra en un diseño exploratorio de carácter explicativo secuencial cuantitativo-cualitativo (Hernández-Sampieri y Mendoza, 2018). El mismo, hace referencia a la utilización de un abordaje tanto cuantitativo como cualitativo en función de poder hacer visible la convergencia de los resultados con el objeto de fortalecer el análisis.

EntreDiversidades. Revista de Ciencias Sociales y Humanidades, Vol. 8, Núm. 2 (17), julio-diciembre 2021. Páginas: 99-118 ISSN-e: 2007-7610. https://doi.org/10.31644/ED.V8.N2.2021.A05 
De esta manera, para el estudio de los mundos semánticos se hizo uso del análisis lexicométrico mediante el método de Reinert a través del software Iramuteq — Interface de R pour les Analyses Multidimensionnelles de Textes et de Questionnaires- (Ratinaud, 2009). Este análisis parte de una premisa común: todos los grupos expresan sus discursos a través un sistema de mundos lexicales, o mundos sintagmáticos propios. Estos mundos pueden contradecirse, complementarse o sucederse unos a otros, quedando en el conjunto de estos mundos el significado de las representaciones sociales (Alba, 2004).

Aunque todos los comentarios se reconocen como expresiones libres y espontáneas, el origen de la información nos remite a aquellos que consideramos como "comentarios directos", es decir, los que se suceden en primer orden, y no a los que se generaron a partir del propio comentario. Así, estos se gestaron a partir del post que surgió el 6 de noviembre del 2020 en el medio digital en español PlayGround, en base a las elecciones presidenciales en Estados Unidos. Dicha publicación se realizó a través de la página de Facebook, bajo la siguiente consigna: "Pregunta para latinoamericanos: ¿Por qué Trump batió su récord de votos latinos, aun con políticas antimigrantes y racistas?”.

En este sentido, la fuente digital se toma como fuente de información en base al criterio de oportunidad en el contexto contemporáneo de pandemia, considerando el interés que detona la pregunta en un tema que genera amplios debates, en el que los datos obtenidos se tratan desde una perspectiva metodológica de rigurosa.

Si bien usamos el criterio de oportunidad, debemos hacer tres observaciones importantes en el uso de las redes sociales como fuente de datos: 1) la imposibilidad de re-preguntar. Es decir, ante ciertas respuestas de carácter ambiguo es imposible indagar en ellas para aclararlas; 2) la dificultad de definir la muestra según criterios previos, lo que es inherente a las redes masivas y nos obliga a considerar a los usuarios indistintamente, y solo con la información que cada uno de ellos nos aporta a través de sus perfiles; y 3) el inconveniente en discernir, a nivel del estudio, entre perfiles reales y aquellos pagados dirigidos a generar una determinada tendencia — los denominados trolls-.

Consecuentemente, y luego de estas aclaraciones, observamos que la publicación —objeto de nuestra investigación- generó un número importante de comentarios que llegó a superar, en las primeras cinco horas, 5 300, y con el transcurrir de los días acumuló más de 7100 de aquellas personas que se sintieron identificadas y a su vez interpeladas como latinos y que no necesariamente residen en el territorio de los Estados Unidos. A partir de ellos, tomamos los primeros 1396 comentarios directos — criterio de saturación empírica一, los que a su vez los discriminamos por género — según datos aportados por el perfil de los comentarios- De esta manera, el corpus lexical de comentarios directos quedó conformado por 419 mujeres, 890 varones y 87 sin posibilidad de determinación de género.

El análisis lexicométrico se llevó adelante en dos etapas. Una primera, donde a través de la Clasificación Jerárquica Descendente se analizó el corpus integrado por los 1396 comentarios directos — mujeres, varones y de género indeterminado-, lo que nos posibilitó establecer las clases que se interpretan como campos léxicos o semánticos que pueden dar cuenta de teorías, conocimientos del sentido común o aspectos de una misma representación (Justo y Camargo, 2014), evocando formas de pensar sobre nuestro objeto.

EntreDiversidades. Revista de Ciencias Sociales y Humanidades, Vol. 8, Núm. 2 (17), julio-diciembre 2021. Páginas: 99-118 ISSN-e: 2007-7610. https://doi.org/10.31644/ED.V8.N2.2021.A05 
Posteriormente, en la segunda etapa, se separó en dos corpus según géneros, tomando en cuenta solamente el subcorpus integrado por los discursos de las mujeres -419 comentarios directos - y el subcorpus integrado por los discursos de los varones - 890 comentarios directos-, sin considerar aquellos comentarios directos (87) en los que, como expusimos, no fue posible determinar el género. Luego se sometió a cada uno de estos subcorpus a un Análisis de Similitud. Esto nos permitió establecer las conexiones que existen dentro de cada subcorpus textual, para identificar los núcleos semánticos y detectar la co-ocurrencia entre cada uno de los elementos o palabras, lo que permite conocer los indicios de conexidad, poniendo en relieve las estructuras discursivas distintivas que operan desde la perspectiva de género en la construcción representacional del voto latino hacia Trump.

\section{Construcción del corpus lexical para Iramuteq}

En primer lugar, se procedió a la transcripción del material textual desde la plataforma digital Facebook de PlayGround. Luego se realizaron las correcciones y adaptaciones ortográficas necesarias para poder correr el análisis de datos mediante el software Iramuteq.

La utilización de este software se estableció en base a los siguientes criterios: a) Evidencia empírica de diversos trabajos de investigación que demuestran su utilidad (Alba, 2004; Ratinaud, 2009; Justo y Camargo, 2014; Ortega y Liloff, 2020); b) Software y materiales de consulta de acceso libre; y c) Experiencia en su uso adquirida en el campo de las investigaciones de las representaciones sociales. Por su parte, el corpus textual se acondiciona para su correcta lectura por parte del programa Iramuteq a partir de dos etapas esenciales:

1. Definición de variable categórica: en nuestra investigación las variables fundamentales que definieron los subcorpus textuales fueron: el género $-\mathrm{v}$ varón $-\mathrm{m}$ mujer-

2. Codificación y correlación: esta etapa consiste en preparar el texto para la correcta lectura por parte del software, de lo contrario el programa arrojará error en la lectura impidiendo llevar adelante el análisis. Por ejemplo, la eliminación o reemplazo de caracteres especiales como comillas o apóstrofes dentro del texto, el cambio de mayúsculas por minúsculas, etc. (Salviati, 2017).

A partir de esto el "corpus lexical” quedó configurado, en primera instancia, para el análisis de Clasificación Jerárquica Descendente, y luego, en una segunda instancia, al separarlo por género para el Análisis de Similitud; en ambos casos se analizó a través del software Iramuteq.

EntreDiversidades. Revista de Ciencias Sociales y Humanidades, Vol. 8, Núm. 2 (17), julio-diciembre 2021. Páginas: 99-118 ISSN-e: 2007-7610. https://doi.org/10.31644/ED.V8.N2.2021.A05 


\section{Análisis de los resultados}

El corpus lexical adoptó las siguientes características estructurales: 1633 segmentos de textos provenientes de los 1396 comentarios directos_- con 35766 ocurrencias —palabras—, de las cuales 3027 se consideran hápax — palabras que aparecen una sola vez—. Del total de palabras, se evidenciaron 5099 formas diferenciadas — sustantivos, verbos, adjetivos, etc.- .

\section{Resultado del análisis de la Clasificación Jerárquica Descendente}

Antes de presentar los resultados del análisis es importante tener en cuenta que el método utilizado de Reinert parte de establecer que las palabras que utilizamos a diario no son independientes unas de otras, por el contrario, se encuentran integradas en redes o mundos semánticos que otorgan sentido, a la vez que ponen de manifiesto la manera en que los sujetos construyen la realidad en torno a los objetos de su interés (Reinert, 1987). Así, al identificar el grupo de palabras que caracterizan un objeto dado, se puede identificar el significado de ese objeto para un grupo determinado (Justo y Camargo, 2014). En otras palabras, cada objeto se describe mediante una combinación de palabras y un número limitado de estas (Lahlou, 1994).

De esta manera, permite clasificar los datos en clases denominadas campos léxicos o contextos semánticos, que en términos de representaciones sociales pueden indicar conocimientos de sentido común o campos de imágenes sobre un objeto dado (Triguero, Nascimento-Schulze y Camargo, 1999). Asimismo, se expone como jerárquico descendente ya que parte de un grupo que reúne a la mayoría de los sujetos que dan forma al corpus, para luego dividirlos en clases diferenciales según atributos similares. Es de notar que establecen patrones repetitivos de lenguaje con un alto índice de homogeneidad dividiendo el corpus discursivo solo en tres clases claramente definidas. Es decir, el discurso alcanza un alto grado de uniformidad.

EntreDiversidades. Revista de Ciencias Sociales y Humanidades, Vol. 8, Núm. 2 (17), julio-diciembre 2021. Páginas: 99-118 ISSN-e: 2007-7610. https://doi.org/10.31644/ED.V8.N2.2021.A05 


\section{Gráfico 1. Dendograma de clases: varones y mujeres}

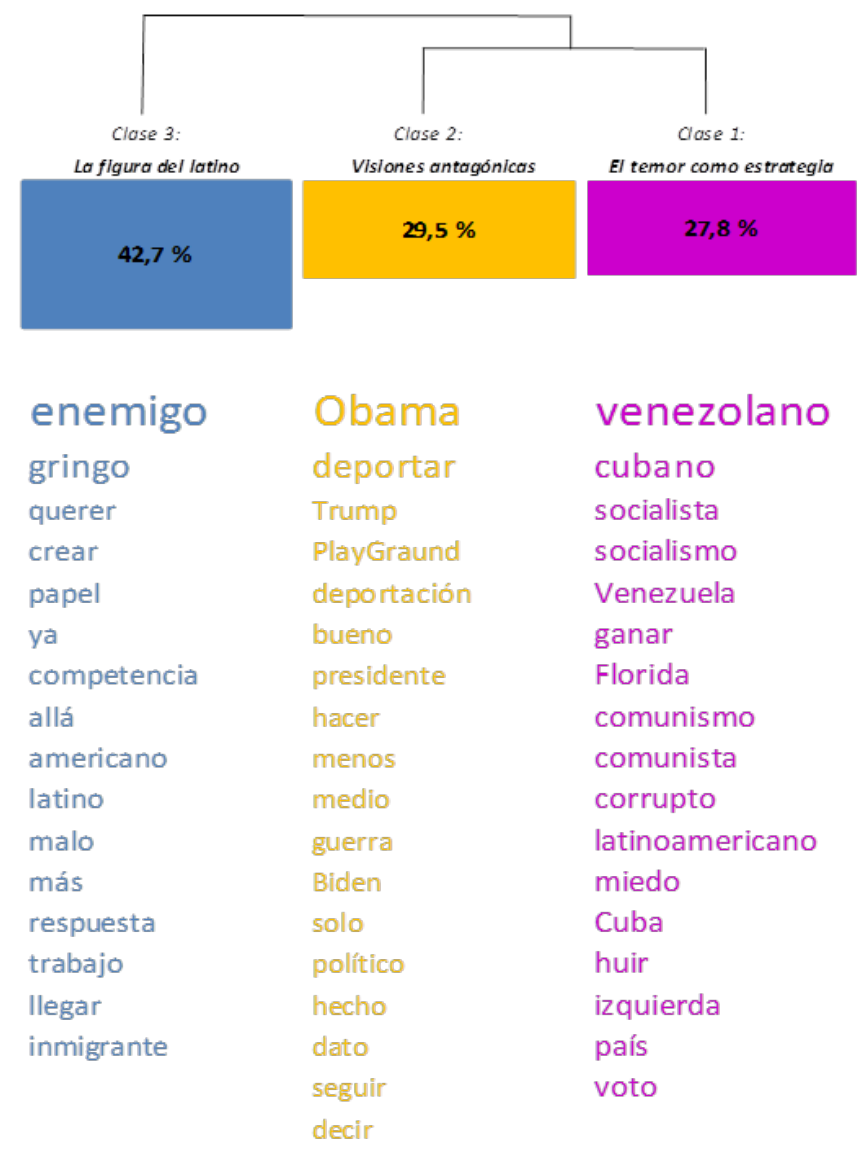

Fuente: Elaboración propia.

Clase 3. La figura del latino: esta clase pone en evidencia un amplio porcentaje de patrones repetitivos - ocurrencias o palabras - en el corpus lexical. Así, el 42,7\% de los segmentos de textos expresan un pensamiento o conocimiento común entre la población que dio su opinión en Facebook, dando cuenta de cómo se estructura la representación social del voto latino a favor de Trump. Su configuración emerge con base en dos figuras. Por un lado, la del "enemigo", en la que el voto a Trump es percibido como una "traición" entre los propios latinos, quedando claramente diferenciados y caracterizados por ellos mismos en dos grupos, el de los latinos ya establecidos de manera legal en los Estados Unidos — los traidores_-, y aquellos que desean emigrar o que se presentan como inmigrantes indocumentados - los traicionados-. A su vez, estos últimos son categorizados como una amenaza por los del primer grupo, al punto tal que estas diferencias se plasman en la siguiente frase: "no existe peor enemigo para un latino que otro latino".

Por otro lado, también se enfatiza en la figura del "gringo", entendida como la del extranjero, es decir, de manera despectiva y referida a aquellos latinos que radican permanentemente en Estados Unidos y por el hecho de obtener su estatus de residente legal o ciudadano norteamericano —-papeles"_, se perciben con cierta superioridad, asumiendo posturas de corte racista con 
sus pares indocumentados, y a su vez tomando parte de su identidad social del grupo de estadounidenses blancos. Esta situación la podemos ver reflejada en varios segmentos de textos bajo la frase: "se creen más gringos que los mismos gringos".

Clase 2. Visiones antagónicas: aquí el discurso se organiza con ocurrencias presentes en un $29,5 \%$ en el corpus, y se relaciona con la construcción de una contraposición entre el tratamiento del latino inmigrante por parte de las presidencias de Obama, por un lado, y Trump, por otro.

En este sentido, se deja ver en el propio corpus lexical una inclinación marcada en presentar la gestión de Obama como una de las que más deportaciones de inmigrantes ilegales ha realizado, en contraposición a la gestión de Trump que, si bien se basó en un discurso antiinmigrante, solo se trató de un discurso populista pero que no se llevó a los hechos.

Clase 1. El temor como estrategia: las ocurrencias que componen esta clase representan el 27,8\% del corpus total, y se constituye en base al discurso que apela a construir en Biden la figura representativa de los gobiernos autoritarios de Latinoamérica, más concretamente asociada a los gobiernos de Venezuela y Cuba. En este sentido, Trump se dirige al componente emocional — miedo- - que se proyecta en los recuerdos de aquellos inmigrantes que han sido marcados por los regímenes autoritarios del chavismo o castrismo, entre otros. En otras palabras, Trump trató de construir una figura de Biden asociada a la idea de una ideología de izquierda totalitarista no democrática, y en ello al miedo de algunos latinos de repetir historias desagradables de sus países de origen, lo que hizo que se optara por el voto favorable a Trump.

La Clasificación Jerárquica Descendente posibilitó evidenciar los mundos lexicales entorno a los que se construye el voto latino en favor de Trump, al igual que cómo se modulan cada una de las clases que lo componen.

Así, se asumen dos grupos antagónicos, aquellos latinos residentes legales o ciudadanos y aquellos con intenciones de emigrar o indocumentados, y desde esta diferencia se categorizan ellos mismos como los enemigos, la competencia, los gringos, etc., lo cual sumado al miedo sobre que la gestión Biden se apropie de ciertos modos de gobiernos de izquierda pudo haber volcado la balanza del voto latino hacia Trump.

Además, resulta de interés develar los posibles sentidos que toma nuestro objeto de análisis a la hora de considerar la perspectiva de género, situación por la cual se realiza la segunda etapa de la investigación.

\section{El discurso desde la perspectiva de los comentarios del género femenino}

El subcorpus analizado desde la perspectiva de género correspondiente a las mujeres estuvo integrado por 419 comentarios directos — 504 segmentos de texto- - dentro del cual presentó 11333 ocurrencias — palabras_- de las cuales 1557 se consideran hápax —palabras que aparecen una sola vez-. Del total de palabras, se evidenciaron 2447 formas diferenciadas — sustantivos, verbos, adjetivos, etc.- - Dicho subcorpus sigue la ley de Zipf, es decir, que independientemente del tamaño del texto que tomemos para nuestro estudio la proporción en la frecuencia de aparición de las palabras siempre se cumple.

EntreDiversidades. Revista de Ciencias Sociales y Humanidades, Vol. 8, Núm. 2 (17), julio-diciembre 2021. Páginas: 99-118 ISSN-e: 2007-7610. https://doi.org/10.31644/ED.V8.N2.2021.A05 


\section{Resultados del Análisis de similitud}

Este tipo de análisis nos permitió identificar dentro del subcorpus — mujeres - ciertos aspectos o núcleos semánticos preponderantes e identificar la relación de fuerza y co-ocurrencia a modo de árbol máximo.

En cuanto a la interpretación del gráfico, se debe considerar las formas o palabras que se encuentran en cada uno de los nodos y la interrelación en las corrientes o agrupamientos establecidas por los distintos colores. Asimismo, el tamańo de los nodos representa la frecuencia - a mayor tamaño, mayor frecuencia-, y los enlaces muestran la co-ocurrencia - a mayor grosor de enlace, mayor co-ocurrencia entre las palabras- (Ruiz Bueno, 2017).

De esta manera, podemos observar cuatro corrientes que se centran en la figura determinada por la forma lexical "latino" y cuya fuerza de co-ocurrencia se encuentra fuertemente enlazada a la forma lexical "Trump". Estas corrientes, que a continuación analizamos, ponen de manifiesto el conocimiento del sentido común que las mujeres le atribuyen al voto latino hacia Trump.

\section{Gráfico 2. Análisis de similitud, árbol máximo, mujeres}

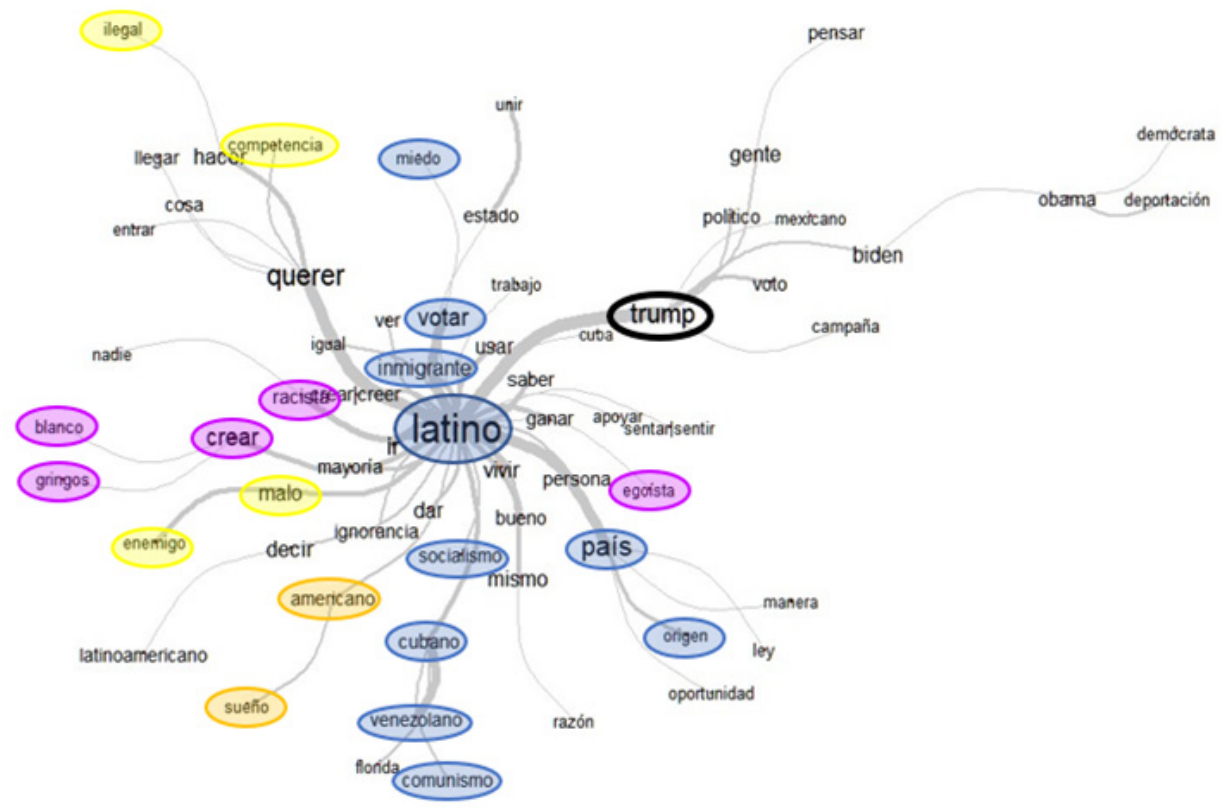

Fuente: Elaboración propia. 
Podemos observar que las personas de género femenino que han brindado una respuesta a la pregunta planteada por PlayGround, y que su vez hemos tomado como muestra, ponen de manifiesto que el voto hacia Trump se relaciona directamente con la condición legal o ilegal en términos de estatus migratorio, en donde la figura del latino en condiciones de indocumentado, ilegal, o incluso aquellos casos en que tienen intenciones de emigrar, se encuentra cargada de aspectos negativos y cuya entrada al país se debe evitar, de ahí que aquellos que han conseguido cierta estabilidad en cuanto a su estatus legal de residentes o ciudadanos — muchos de ellos en condiciones de sufragar - se asumen por sus pares bajo las formas lexicales de "racistas", "egoístas" o "creerse o sentirse superiores". Además, la figura "Trump" se presenta como un nodo fuerte en esta construcción. A su vez, el "miedo" a repetir historias asociadas al "comunismo" o "socialismo" de sus países de origen, tales como Cuba o Venezuela, actúa como un factor importante en la emisión del voto.

En este mismo sentido, la figura del votante se construye sobre la base de una persona latina que se asume de tez blanca y con un fuerte nacionalismo - forma lexical bajo la ocurrencia de "gringo"-, que roza aspectos xenófobos hacia sus pares indocumentados o con intenciones de emigrar - "entrar"- . Desde la perspectiva de los comentarios femeninos analizados, estos aspectos tienen sus raíces en ver al otro inmigrante, una posible "competencia" ante el "sueño americano", representando lo malo y primando una visión clasista de tinte racista.

Así, se construyen dos figuras de la persona latina: por un lado, los que se perciben como estadounidenses en base a su "condición legal resuelta" y, por ello, como superiores, y, por otro, aquellos indocumentados que son representados como "la competencia" o incluso como "los enemigos".

Por otro lado, también, podemos observar relaciones secundarias como aquellas que justifican el voto hacia Trump dado el historial de deportaciones de los gobiernos de carácter demócrata, poniendo como ejemplo la administración Obama.

\section{El discurso desde la perspectiva de género masculino}

$\mathrm{Al}$ igual que en el género femenino, en la interpretación del gráfico se debe considerar las corrientes o agrupamientos que dan significado al discurso, como así también las formas o palabras que se encuentran en los nodos, tomando en cuenta que su tamaño se relaciona con la frecuencia y el grosor de los enlaces con la co-ocurrencia.

El subcorpus analizado desde la perspectiva de género correspondiente a los varones estuvo integrado por 890 comentarios directos - 1 032 segmentos de texto-, con 22322 ocurrencias - palabras — en los mismos, de las cuales 2402 se consideran hápax. Del total de palabras, se evidenciaron 3859 formas diferenciadas. Dicho subcorpus sigue la ley de Zipf.

\section{Resultados del Análisis de similitud}

Observamos que las personas de género masculino que han brindado una respuesta a la pregunta planteada por PlayGround, y que a su vez hemos tomado como muestra, ponen de manifiesto que el voto hacia Trump se consolida, al igual que en el género femenino, a partir de un fuerte énfasis en la figura del "latino", pero desde una perspectiva centrada con mayor fuerza en su

EntreDiversidades. Revista de Ciencias Sociales y Humanidades, Vol. 8, Núm. 2 (17), julio-diciembre 2021. Páginas: 99-118 ISSN-e: 2007-7610. https://doi.org/10.31644/ED.V8.N2.2021.A05 
percepción como lo "malo", como un "enemigo", en el que la figura de Trump se presenta como un nodo de importancia en esta construcción.

\section{Gráfico 3. Análisis de similitud, árbol máximo, varones}

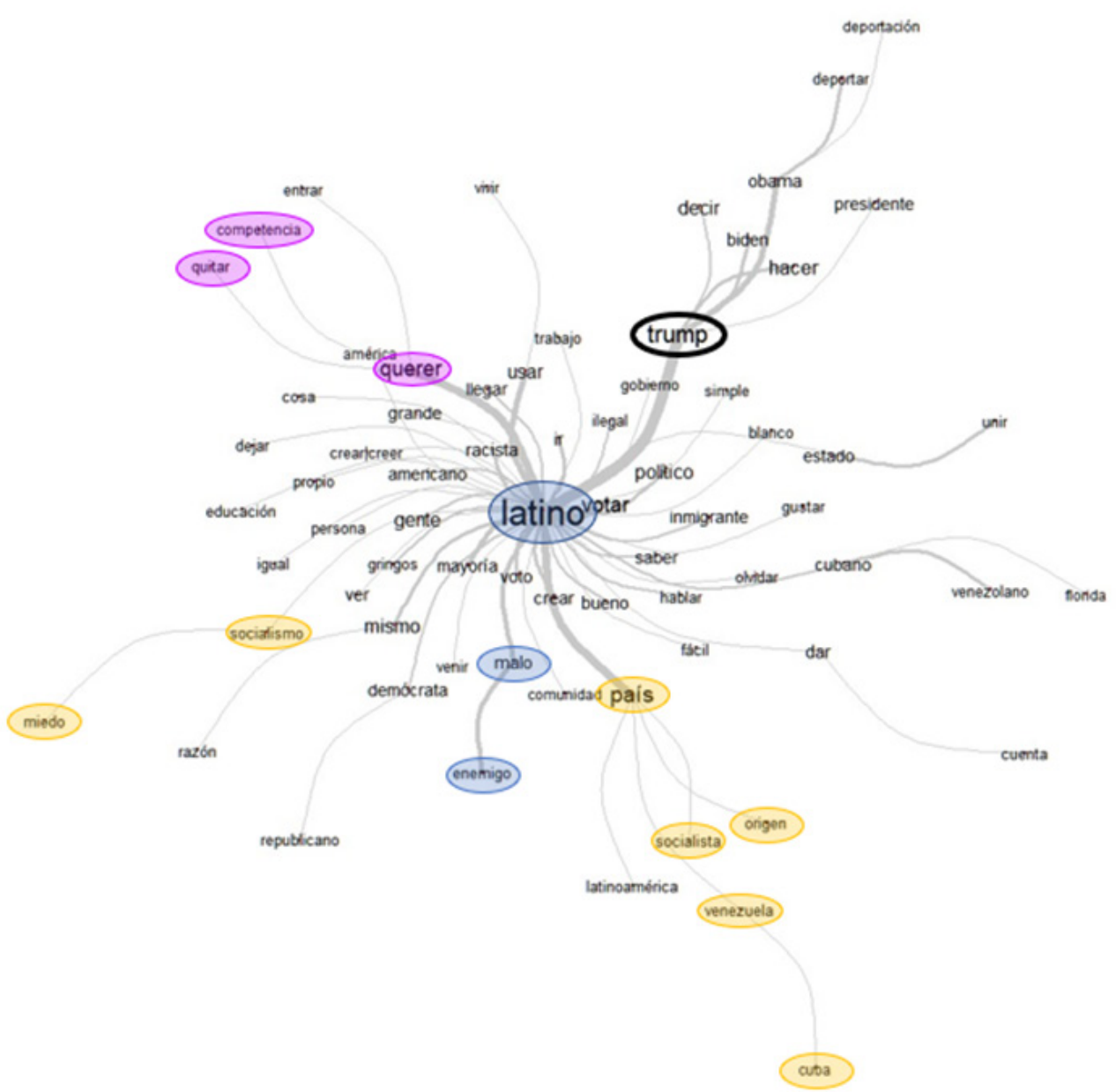

Fuente: Elaboración propia.

En esta situación, aquel latino con intenciones de emigrar o inmigrante indocumentado se presenta como una "competencia" que hay que "quitar", ya que atenta contra las oportunidades laborales y representa aquellos aspectos negativos que se quiere dejar atrás.

Por otra parte, al igual que lo planteado por el género femenino, el miedo a ideologías de corte socialista o comunista de ciertos gobiernos latinoamericanos endilgados a la figura de Biden, y representados en especial por los gobiernos de Venezuela y Cuba, juegan un papel preponderante a la hora de emitir el voto. 


\section{Conclusión}

El análisis lexicométrico nos permitió establecer una estrategia adecuada para el estudio de las representaciones sociales del voto latino hacia Trump, rescatando la expresión de sentido común. El uso de esta estrategia fue posible a través de la prensa digital, utilizando para ello la plataforma de Facebook.

Diferentes investigaciones que han adoptado estrategias similares pusieron de manifiesto la relevancia de este tipo de estudios de manera de poder evidenciar tanto el contenido como la conexidad o interrelación que se hacen visible en los sintagmas que componen los mundos lexicales predominantes y de donde toman forma las representaciones sociales. En otras palabras, estos mundos lexicales expresaran las creencias, ideas, opiniones, etc. que toman forma en el sentido común de los sujetos.

De esta manera, los resultados a los que arribamos nos permitieron poner en evidencia, por un lado, la estructura discursiva que se construye desde la propia perspectiva de los actores que se sintieron interpelados e identificados ellos mismos como latinos, mientras que, por otro, nos posibilitó poner al descubierto las lógicas imperantes en estas construcciones. En otras palabras, accedimos al conocimiento del sentido común, que no es otra cosa que las propias representaciones sociales del grupo de estudio. Es decir, rescatamos las voces de los propios actores a través de sus expresiones.

Así, fue posible visualizar aquellos aspectos concretos sobre los cuales se construyeron los diferentes nodos o mundos lexicales de las personas de nuestro estudio, las relaciones que se establecen entre estos nodos tanto en torno a la fuerza como en la co-ocurrencia, como así también los aspectos relevantes desde la perspectiva de género.

Sintetizando, observamos que las representaciones sociales del voto latino se configuran en base a solo tres clases o construcciones discursivas — descriptas en el dendograma, Gráfico 1—. Estas ponen de manifiesto la existencia de dos grupos diferenciados que intervienen en la construcción del voto en favor a Trump; en ambos grupos los integrantes se identifican como latinos, pero se diferencian fundamentalmente según pueda suponerse el estatus legal de ciudadanos o residentes, por un lado, o de indocumentados, por otro, situación suficiente para categorizarse entre ellos como los enemigos, la competencia, el que se cree gringo, o que se siente superior, etc.

Es esta diferenciación la que conforma, en parte, la dinámica para inclinar el voto latino hacia Trump, en donde aquellos latinos en condiciones de sufragar - cuyo estatus legal se encuentra resuelto-, toman parte de su identidad social asumiéndose integrantes de los grupos de estadounidenses nacionalistas partidarios del discurso etnocentrista de tinte xenófobo y racista. Situación que a la vez también muestra el desplazamiento del voto latino hacia Trump en función de comprender su política migratoria en términos más duros que la de los gobiernos demócratas como el de Obama, figura esta última asociada a Biden.

Dicho de otro modo, la retórica construida por Trump en base a las políticas antimigratorias es la retórica que posibilita construir el "sueño americano", libre de enemigos y de competencia, que en propias palabras de Trump se asume como "libre de los malos latinos".

Asimismo, desde la perspectiva de género se evidencian ciertos aspectos que se acentúan. Para el caso de los varones, aquellos latinos que votaron a Trump ven en la figura del propio

EntreDiversidades. Revista de Ciencias Sociales y Humanidades, Vol. 8, Núm. 2 (17), julio-diciembre 2021. Páginas: 99-118 ISSN-e: 2007-7610. https://doi.org/10.31644/ED.V8.N2.2021.A05 
latino un enemigo, la personificación de lo malo, aquella competencia que hay que eliminar o quitar. Desde la perspectiva de las mujeres, los votantes latinos de Trump se perciben como "de creerse superiores", a la par que a los indocumentados o con intenciones de emigrar, de hecho, se les endilga aspectos de índole racista. De esta manera, el latino que tiene su estatus de residente o ciudadano se supone de tez blanca — asumido como el verdadero estadounidense-, con un fuerte nacionalismo — gringo-, primando una visión clasista xenófoba.

Es de notar que en ambos casos se presenta la figura de Trump como un nodo fuerte en estas construcciones, donde el miedo a repetir historias del comunismo o socialismo de países como Cuba o Venezuela se transforma en un fuerte proveedor de identidad de la comunidad latina.

En resumen, el voto latino en favor de Trump se asume desde la propia comunidad latina como construido por las desigualdades sociales imperantes a partir una visión capitalista, donde el otro, extranjero - latino en nuestro caso- es excluido y envilecido por sus propios pares, que al tener su estatus legal resuelto se perciben como estadounidenses, siendo esta condición suficiente para despojar al extranjero de toda subjetividad, a punto tal de convertirlo en un extraño, una amenaza que es necesario prescindir o eliminar.

\section{Bibliografía citada}

Abric, Jean-Claude (2017 [1989]). "L'etude expérimentale des representations sociales", en Jodelet, Denise (ed.). Les représentations sociales, séptima edición. París, Francia: Presses Universitaires de France, pp. 205-223.

Alba, Martha de (2004). "El método ALCESTE y su aplicación al estudio de las representaciones sociales del espacio urbano: el caso de la ciudad de México". Papers on Social Representations [en línea], Vol. 13, pp. 1.1-1.20. Disponible en: https://psr.iscte-iul.pt/index.php/PSR/ article/view/357 (Consultado el 20 de noviembre de 2020).

Ariza, Marina y Gutiérrez, Silvia (2020). "Emociones colectivas y estrategias argumentativas ante la inmigración ilegal en los discursos de Donald Trump”, en Ariza, Marina (coord.). Las emociones en la vida social: miradas sociológicas. Ciudad de México, México: Universidad Nacional Autónoma de México, pp. 215-253. Disponible en: https://www.iis.unam.mx/ las-emociones-en-la-vida-social-miradas-sociologicas/ (Consultado el 4 de diciembre de 2020).

Castro, Blanca (2020). "Elecciones EE.UU. Mitos y verdades del voto latino: por qué estamos tan equivocados". Euronews [en línea], 5 de noviembre. Disponible en: https:// es.euronews.com/2020/10/22/mitos-verdades-voto-latino-elecciones-estados-unidosbiden-trump-2020 (Consultado el 10 noviembre de 2020).

Cilluffo, Anthony y Fry, Richard (2019). "An Early Look at the 2020 Electorate”, Pew Research Center [en línea], 30 de enero. Disponible en: https://www.pewsocialtrends.org/essay/anearly-look-at-the-2020-electorate/ (Consultado el 12 de noviembre de 2020).

EntreDiversidades. Revista de Ciencias Sociales y Humanidades, Vol. 8, Núm. 2 (17), julio-diciembre 2021. Páginas: 99-118 ISSN-e: 2007-7610. https://doi.org/10.31644/ED.V8.N2.2021.A05 
Corona, Sonia (2020). "Biden corteja el voto latino en Florida ante el avance de Trump". El País [en línea], 16 de septiembre. Disponible en: https:/elpais.com/internacional/2020-09-16/ biden-corteja-el-voto-latino-en-florida-ante-el-avance-de-trump.html (Consultado el 10 de noviembre de 2020).

Etura Hernández, Dunia, Víctor Gutiérrez Sanz y Virginia Martín Jiménez (2017). "La cultura mediática y el discurso posmachista: análisis retórico de facebook ante la violencia de género”. Investigaciones Feministas [en línea], 8 (2), pp. 369-384. doi: http://dx.doi. org/10.5209/INFE.55034 (Consultado el 4 de diciembre de 2020).

Farr, Robert (1986). "Las representaciones sociales", en Moscovivi, Serge (ed.). Psicología social. Pensamiento y vida social. Psicología social y problemáticas sociales, Tomo II. Barcelona, España: Paidós, pp. 495-506.

Gutiérrez, Silvia y Cuevas, Yasmín (2012). "Representaciones sociales de Enrique Peńa Nieto, candidato a la presidencia de México 2012-2018, en la prensa escrita”. Cultura y representaciones sociales [en línea], 7 (13), pp. 63-95. Disponible en: http://www.culturayrs. unam.mx/index.php/CRS/article/view/410/410 (Consultado el 4 de diciembre de 2020).

Hernández-Sampieri, Roberto, Mendoza Torres, Chistian Paulina (2018). Metodología de la investigación. Las rutas cuantitativa, cualitativa y mixta. Ciudad de México, México: Editorial McGraw Hill Interamericana.

Jodelet, Denise (2017 [1989]). "Représentations sociales: un domaine en expansión”, en Les représentations sociales, séptima edición. París, Francia: Presses Universitaires de France, pp. 47-78.

Justo, Ana María y Camargo, Brigido Vizeu (2014). "Estudo qualitativos e o uso de softwares para análises lexicais”, en Novikoff, C., S. R. M. Santos y O. B. Mithidieri (Orgs.). Caderno de artigos: X SIAT \& II Serpro. Rio de Janeiro, Brasil: UNIGRANRIO, pp. 37-54.

Lahlou, Sadi (1994). "L'analyse lexicale". Variances, Núm. 3, pp. 13-24.

Medina, Jennifer (2020). "Lo que los demócratas no entienden del voto latino". The New York Times [en línea], 9 de noviembre. Disponible en: https://www.nytimes.com/ es/2020/11/09/espanol/latinos-voto.html (Consultado el 10 de noviembre de 2020).

Moscovici, Serge (1979). El psicoanálisis su imagen y su público. Buenos Aires, Argentina: Editorial Anesa-Huemul.

Moscovici, Serge (1981). “On Social Representations”, en Forgas, Joseph (ed.). Social Cognition: Perspectives on Everyday Understanding. London, United Kingdom: Academic Press, pp. 18-209.

Moscovici, Serge (2005 [1985]). La era de las multitudes: un tratado histórico de la psicología de las masas. México, D.F., México: Fondo de Cultura Económica.

Noe-Bustamante, Luis, Abby Budiman y Mark Hugo López (2020). "Where Latinos Have the Most Eligible Voters in the 2020 Election". Pew Research Center [en línea], 31 de enero. Disponible en: https://www.pewresearch.org/fact-tank/2020/01/31/where-latinos-havethe-most-eligible-voters-in-the-2020-election/ (Consultado el 12 de noviembre de 2020).

EntreDiversidades. Revista de Ciencias Sociales y Humanidades, Vol. 8, Núm. 2 (17), julio-diciembre 2021. Páginas: 99-118 ISSN-e: 2007-7610. https://doi.org/10.31644/ED.V8.N2.2021.A05 
Ortega Rubí, María Estela (2015 [2011]). “Conceptos básicos de psicología social”, en García Cadena, Cirilo Humberto (comp.). Diccionario temático de psicología. Ciudad de México, México: Trillas, pp. 211-235.

Ortega Rubí, María Estela y Liloff, Gustavo Adolfo (2020). "Las representaciones sociales de la violencia: el caso Fernando Báez a través del análisis lexicométrico de la prensa digital en Facebook". Revista de Investigación del Departamento de Humanidades y Ciencias Sociales [en línea], 9 (17), pp. 63-85. Disponible en: https://rihumso.unlam.edu.ar/index.php/ humanidades/article/view/196/291 (Consultado el 4 de diciembre de 2020).

Padden, Brian y Balderas Iglesias, Verónica (2020). "Votantes latinos por Trump ayudaron a mantener reñida la elección". Voice of America [en línea], 11 de noviembre. Disponible en: https://www.voanoticias.com/estadosunidos/votantes-latinos-por-trump-ayudaronmantener-renida-la-eleccion (Consultado el 12 de noviembre de 2020).

PlayGround (2020). Pregunta para latinoamericanos: ¿Por quéTrump batió su récord de votos latinos, aun con politicas antimigrantes y racistas? [Facebook], 6 de noviembre. Disponible en: https://www.facebook.com/PlayGroundMag/posts/3954527627920417 (Consultado el 6 de noviembre de 2020).

Politico (2016). "Full Text: Donald Trump 2016 RNC Draft Speech Transcript". Politico Magazine [en línea], 21 de julio. Disponible en: https:/www.politico.com/story/2016/07/fulltranscript-donald-trump-nomination-acceptance-speech-at-rnc-225974 (Consultado el 12 de noviembre de 2020).

Ratinaud, Pierre (2009). Iramuteq: interface de R pour les Analyses Multidimensionnelles de Textes et de Questionnaires [software]. Disponible en http://www.iramuteq.org

Reinert, Max (1987). "Classification descendante hiérarchique et analyse lexicale par contexte: application au corpus des poésies d'Arthur Rimbaud". Bulletin de Méthodologie Sociologique, Núm. 13, pp. 53-90.

Rothwell, Jonathan T. y Diego-Rosell, Pablo (2016). "Explaining Nationalist Political Views: The Case of Donald Trump". SSRN [en línea]. doi: http://dx.doi.org/10.2139/ssrn.2822059 (Consultado el 16 de noviembre de 2020).

Rouquette, Michel-Louis (1986). "La comunicación de masas", en Moscovivi, Serge (ed.) Psicología social. Pensamiento y vida social. Psicología social y problemáticas sociales, Tomo II. Barcelona, España: Paidós, pp. 627-647.

Ruiz Bueno, Antoni (2017). Trabajar con Iramuteq: pautas [en línea]. Disponible en: http:// diposit.ub.edu/dspace/bitstream/2445/113063/1/Trabajar con IRAMUTEQ PAUTAS.pdf (Consultado el 4 de diciembre de 2020).

Salviati, Maria Elisabeth (2017). Manual do Aplicativo Iramuteq (versão 0.7 Alpha 2 e R Versão 3.2.3) [en línea]. Planatina, Brasil: Iramuteq. Disponible en: http://www.iramuteq.org/ documentation/fichiers/manual-do-aplicativo-iramuteq-par-maria-elisabeth-salviati (Consultado el 4 de diciembre de 2020).

EntreDiversidades. Revista de Ciencias Sociales y Humanidades, Vol. 8, Núm. 2 (17), julio-diciembre 2021. Páginas: 99-118 ISSN-e: 2007-7610. https://doi.org/10.31644/ED.V8.N2.2021.A05 
Sulbarán Lovera, Patricia (2020). "Joe Biden: cómo los latinos beneficiaron y perjudicaron al presidente electo al mismo tiempo en las elecciones". BBC News Mundo [en línea], 6 de noviembre. Disponible en: https://www.bbc.com/mundo/noticiasinternacional-54833629 (Consultado el 16 de noviembre de 2020).

Tajfel, Henri (1984). Grupos humanos y categorías sociales. Barcelona, España: Heder.

Triguero Veloz, María Cristina, Clélia Maria Nascimento-Schulze y Brigido Vizeu Camargo (1999). "Representaçôes sociais do envelhecimento". Psicologia Reflexão e Crítica [en línea], 12 (2), pp. 479-501. doi: http://dx.doi.org/10.1590/S0102-79721999000200015 (Consultado el 4 de diciembre de 2020).

Yakushko, Oksana (2009). "Xenophobia: Understanding the Roots and Consequences of Negative Attitudes Toward Immigrants". The Counseling Psychologist [en línea], 37 (1), pp. 36-66. doi: https://doi.org/10.1177/0011000008316034 (Consultado el 16 de noviembre de 2020). 